\title{
Investigation of clinical interaction between omeprazole and tacrolimus in CYP3A5 non-expressors, renal transplant recipients
}

This article was published in the following Dove Press journal:

Therapeutics and Clinical Risk Management

3 June 2010

Number of times this article has been viewed

\author{
Paraskevi F Katsakiori' \\ Eirini P Papapetrou ${ }^{2}$ \\ Dimitrios S Goumenos ${ }^{3}$ \\ George C Nikiforidis ${ }^{4}$ \\ Christodoulos S Flordellis \\ Departments of 'Pharmacology, \\ ${ }^{3}$ Internal Medicine-Nephrology, \\ ${ }^{4}$ Medical Physics, School of Medicine, \\ University of Patras, Rion, Greece; \\ ${ }^{2}$ Center for Cell Engineering, \\ Molecular Pharmacology and \\ Chemistry Program, Memorial \\ Sloan-Kettering Cancer Center, \\ New York, NY, USA
}

Background: As proton pump inhibitors share CYP3A4 enzyme with tacrolimus for their hepatic elimination, they potentially affect its pharmacokinetics, most prominently in patients with CYP2C19 or CYP3A5 gene mutations. Our aim was to investigate the impact of omeprazole on tacrolimus pharmacokinetics in CYP3A5 non-expressors, kidney transplant recipients.

Methods: Twelve patients (five males/seven females) were observed for $175 \pm 92.05$ days. Omeprazole (20 mg pos) was administrated for $75.83 \pm 45.17$ days. Immunosuppressant regimen consisted of tacrolimus $(n=12)$, methylprednisolone $(n=10)$, mycophenolate mofetil $(n=11)$, azathioprine $(n=1)$, and everolimus $(n=2)$. Patient's body weight, coadministered drugs, and tacrolimus trough levels were monitored. Aspartate and alanine aminotransferase, $\gamma$-glutamyltransferase, and bilirubin were used for evaluating hepatic function. Tacrolimus kinetics were estimated with daily dose, concentration, dose adjusted concentration, and volume of distribution with and without coadministration of omeprazole. CYP3A5 genotyping was performed with PCR followed by restriction fragment length polymorphism analysis. Statistical analysis was performed with Prism 4 software (GraphPad Software, Inc).

Results: No statistically significant difference was observed in tacrolimus kinetics and hepatic function during coadministration of omeprazole.

Conclusion: Our results let us propose that there is no need for more frequent therapeutic drug monitoring of tacrolimus when coadministrated with omeprazole in CYP3A5 nonexpressors, though prospective studies with more patients and longer observation period are needed to confirm these findings.

Keywords: CYP3A5, omeprazole, renal transplantation, tacrolimus

\section{Introduction}

Proton-pump inhibitors (PPIs) are commonly administrated to transplanted patients to prevent stress-related gastric bleeding or gastrointestinal ulceration. In humans, PPIs are metabolized by cytochrome P450 (CYP) enzymatic system, mainly by CYP2C19 and CYP3A4. ${ }^{1-3}$ Systemic clearance of tacrolimus (TAC), the main immunosuppressant drug agent, is performed via CYP3A4 and CYP3A5. ${ }^{4-6}$ As PPIs and TAC share CYP3A4 enzyme for their hepatic elimination, PPIs may potentially affect TAC pharmacokinetics, most prominently in patients with CYP2C19 or CYP3A5 gene mutations.

The presence of clinically relevant pharmacokinetic drug interaction between omeprazole and TAC remains a matter of controversy. ${ }^{2,3,7-10}$ Omeprazole is metabolized into its major primary metabolites by CYP2C19 with a minor contribution of CYP3A4. ${ }^{2,3}$ In case of CYP2C19 gene mutation (poor metabolizers) or if high doses of omeprazole (40 mg) are given to extensive metabolizers, CYP3A4 becomes the main elimination enzyme for
Correspondence: Paraskevi F Katsakiori Department of Pharmacology, School of Medicine, University of Patras,

Rion, Greece

Tel +30 6937438208

Email vkatsak@med.upatras.gr 
omeprazole. ${ }^{9}$ In vivo studies using human liver microsomes have shown that omeprazole inhibits CYP3A4-mediated metabolism of TAC competitively. ${ }^{7,8}$ Takahashi et al proposed rabeprazole as a safer treatment option than omeprazole in kidney transplant recipients receiving TAC. ${ }^{11}$ Lemahieu et al examined the impact of cimetidine and omeprazole on TAC exposure and on CYP3A4/PGP activity in vivo and concluded that switching treatment with cimetidine to omeprazole in renal transplant recipients is associated with a decrease of dose/ weight normalized trough levels of TAC. ${ }^{12}$ In contrast, Pascual et al estimated the potential interaction between omeprazole and TAC in renal transplant recipients and concluded to absence of important drug interaction. ${ }^{10}$

Defective CYP3A5 genotype may reveal potential CYP3A4-mediated drug interaction between TAC and omeprazole. CYP3A5 may account for more than $50 \%$ of whole hepatic CYP3A in individuals who express it. Therefore, it is the main genetic factor responsible for the interindividual variation of kinetics of drugs that are metabolized by CYP3A family. ${ }^{13}$ Although CYP3A5 polymorphisms seem to have greater importance than those of CYP3A4, nonexpressors may sometimes not be distinct because many drugs are metabolized by both CYP3A5 and CYP3A4. ${ }^{14}$ The most important polymorphism in CYP3A5 gene is CYP3A5*1 (A6986G) which is situated in intron 3. ${ }^{4-6}$ Individuals carrying at least one CYP3A5*1 (g6986A) allele express CYP3A5 whereas subjects homozygotes for CYP3A5*3 (g6986G) allele do not express CYP3A5 protein. ${ }^{13}$

The aim of the present study was to investigate the impact of omeprazole on TAC pharmacokinetics in CYP3A5 nonexpressors, kidney transplant recipients.

\section{Subjects and methods Subjects}

Twelve individuals (five males/seven females), who received a kidney transplant for end stage chronic renal insufficiency and attended the Outpatient Clinic of Nephrology in our institution, were selected to participate in the study. Informed consent was obtained from each participant.

Patients had received the kidney transplant $699.83 \pm 969$. 13 days ago, the average observation time was $175 \pm 92.05$ days and omeprazole treatment (20 mg pos) was administrated for $75.83 \pm 45.17$ days. The immunosuppressant regimen consisted of TAC $(\mathrm{n}=12)$, methylprednisolone $(\mathrm{n}=10)$, mycophenolate mofetil $(\mathrm{n}=11)$, azathioprine $(\mathrm{n}=1)$, and everolimus $(\mathrm{n}=2)$. TAC was taken twice a day and its blood concentration was measured 12 hours post night dose at repeated time points. Patient's body weight, coadministered drug agents, TAC trough levels, and blood chemistry were monitored during the study time. TAC dose adjusted concentration and volume of distribution (dose/ concentration ratio) were calculated.

Concomitant medication was allowed only if it had been started 1 month before the initiation of the study especially if the administrated drugs influenced the kinetics of tacrolimus or omeprazole. Coadministrated treatment included drug agents for coronary heart disease, diabetes mellitus, thyroid gland disorders, hypertension, hyperuricemia, hypertriglyceridemia/hyperlipidemia, osteoporosis, anemia (iron-deficiency etc), magnesium disorders, and antibiotic prophylaxis.

\section{CYP3A5 genotype determination}

Genomic DNA was extracted from the $200 \mu \mathrm{L}$ ethylenediaminetetracetic acid-treated whole blood sample with the use of QIAamp DNA Blood kit (QIACEN GmbH). CYP3A5 genotyping was performed with PCR followed by restriction fragment length polymorphism analysis (RFLP). In accordance to van Schaik et al the forward primer used was 5'-CATCAGTTAGTAGACAGATGA-3' and the reverse one 5'-GGTCCAAACAGGGAAGAAATA-3' ${ }^{13}$ These primers amplified a 293-bp fragment of CYP3A5. PCR conditions were $1 \mathrm{~min}$ at $94^{\circ} \mathrm{C}, 40$ cycles of $1 \mathrm{~min}$ at $94^{\circ} \mathrm{C}, 1 \mathrm{~min}$ at $55^{\circ} \mathrm{C}, 1 \mathrm{~min}$ at $72^{\circ} \mathrm{C}$, and a final extension of $7 \mathrm{~min}$ at $7^{\circ} \mathrm{C}$. Digestion of PCR product was performed with the use of SspI endonuclease (New England BioLabs Inc.) and the digestion products were separated with 3.5\% agarose/Trisborate EDTA gel electrophoresis and ethidium bromide staining (Figure 1). CYP3A5*1/*1 genotype gave 148-, 125-, and 20-bp bands; CYP3A5*3/*3 genotype 168- and 125-bp bands; and CYP3A5*1/*3 genotype 168-, 148-, 125-, and 20-bp. ${ }^{13}$

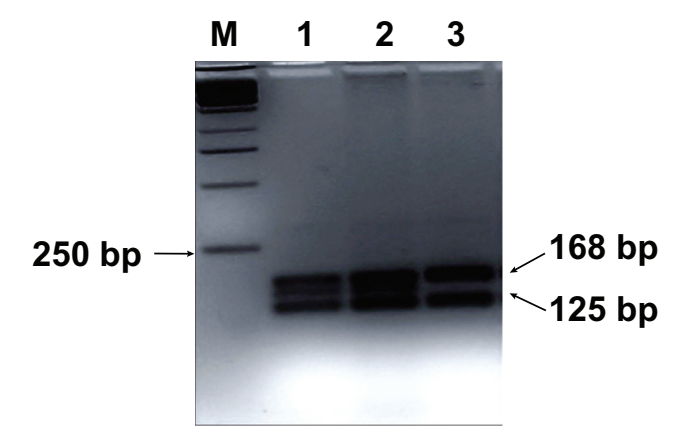

Figure I RFLP for CYP3A5. Lane M, base pair marker (250-bp DNA ladder); lanes I-3, Sspl-digested PCR products from three PCR products. CYP3A5*3/3 genotype gives 168- and 125-bp bands (lane 3) and CYP3A5*I/3 genotype gives I68-, I48-, I 25-, and 20-bp (lanes I and 2). The 20-bp band is not visible. CYP3A5 $5^{*} / /^{*} \mid$ genotype is not seen in this picture. Analysis on a $3.5 \%$ agarose/Tris-borate-EDTA gel. 


\section{Statistical analysis}

TAC pharmacokinetics were estimated with the use of TAC daily dose, concentration, dose adjusted concentration, and volume of distribution (dose/concentration ratio), with and without coadministration of omeprazole. Aspartate aminotransferase, alanine aminotransferase, $\gamma$-glutamyltransferase, and bilirubin were used for the evaluation of hepatic function.

Statistical calculations and analyses were performed with the use of Prism 4 (GraphPad Software, Inc) statistical software package. Continuous data were tested with Kolmogorov's normality test to estimate whether originated from normal distribution or not. Student's $t$-test was used for testing the significance of difference of variables that passed the normality test. Mann-Whitney test was used for continuous variables that did not pass the normality test. All statistical tests performed were two-sided. The threshold of statistical significance was set at $5 \%(a=0.05)$.

\section{Results}

The characteristics of the study population are presented in Table 1. The etiology of the primary kidney disease was unknown $(\mathrm{n}=2)$, cystoureteral reflux $(\mathrm{n}=2)$, polycystic kidney disease $(\mathrm{n}=1)$, diabetic nephropathy $(\mathrm{n}=1)$, Alport syndrome $(n=1)$, eclampsia $(n=1)$, antiphospholipidic syndrome/systemic lupus erythematosus ( $\mathrm{n}=1)$, nephrolithiasis $(\mathrm{n}=1)$, nephronophthisis $(\mathrm{n}=1)$, and IgA nephropathy $(\mathrm{n}=1)$.

No statistically significant difference was observed in TAC pharmacokinetics during the coadministration of omeprazole (Table 2). No statistically significant difference was observed in aspartate aminotransferase, alanine aminotransferase, $\gamma$-glutamyltransferase, and bilirubin during the concomitant use of omeprazole (Table 2).

\section{Discussion}

Defective CYP3A5 genotype in renal transplanted patients could reveal the CYP3A4-mediated drug interaction between TAC and omeprazole. The contribution of CYP3A5 to the

Table I Characteristics of patient population

\begin{tabular}{ll}
\hline Characteristic & \\
\hline Age (years, mean (SD)) & $35.08($ I6.3I) \\
Gender (male/female) & $5 / 7$ \\
Weight (kg, mean (SD)) & $69.63(8.46)$ \\
Transplantation number (first/second) & $10 / 2$ \\
Cadaver transplant donor & 12 \\
Age at the onset of the chronic renal deficiency & $30.58(15.53)$ \\
(years, mean (SD)) & \\
\hline
\end{tabular}

interaction between TAC and omeprazole remains unclear. Seventy-five percent of whites and $50 \%$ of African Americans do not express functional CYP3A5. ${ }^{14}$ In the Greek population, the CYP3A $5 * 3$ allele shows an allelic frequency of $94.35 \%$ whereas individuals homozygous for CYP $3 \mathrm{~A} 5 * 3$ show a frequency of $88.69 \% .{ }^{15}$ In our study, the participants were CYP3A5 nonexpressors to ensure that TAC is metabolized through CYP3A4 and thereby, share this cytochrome with omeprazole.

To our knowledge, up to now clinical significance of pharmacokinetic drug interactions between PPIs and TAC has mainly been investigated in case reports and inadequately estimated in clinical trials. Namely, no clear clinically relevant interaction between TAC and omeprazole has been reported and the results of the studies are controversial. Although omeprazole inhibits the in vitro metabolism of TAC by human liver microsomes, no clinical study is available on the relevance of such an interaction among transplant patients. ${ }^{78}$ Additionally, although interaction of omeprazole with TAC may involve inhibition of hepatic and intestinal CYP3A4, intestinal PGP, and pharmacokinetic characteristics of omeprazole, the only reported interactions between TAC and other PPI have been described in subjects with CYP2C19 gene variants. ${ }^{16-18}$ More specifically, increased blood concentration of omeprazole can cause CYP3A4 overload and result in interaction in this pathway in patients with CYP2C19 gene mutations as pharmacokinetic profiles of omeprazole and lanzoprazole depend on the CYP2C19 genotype status. ${ }^{11,17,19}$

Because PPIs and TAC share the CYP3A4 system for their hepatic elimination, PPIs may potentially inhibit TAC metabolism via CYP3A4 thereby increasing drug blood

Table 2 Tacrolimus pharmacokinetics and hepatic function with and without coadministration of omeprazole

\begin{tabular}{llll}
\hline Parameter & $\begin{array}{l}\text { With } \\
(\text { mean } \pm \text { SD) }\end{array}$ & $\begin{array}{l}\text { Without } \\
(\text { mean } \pm \text { SD) }\end{array}$ & $P$ \\
\hline $\begin{array}{l}\text { Concentration } \\
(\mathrm{ng} / \mathrm{mL})\end{array}$ & $9.80 \pm 3.70$ & $9.32 \pm 3.86$ & 0.3409 \\
$\begin{array}{l}\text { Daily dose } \\
(\mathrm{mg} / \mathrm{kg} / \mathrm{day})\end{array}$ & $0.10 \pm 0.05$ & $0.11 \pm 0.07$ & 0.2335 \\
$\begin{array}{l}\text { Concentration/dose } \\
((\mathrm{ng} / \mathrm{mL}) /(\mathrm{mg} / \mathrm{kg}))\end{array}$ & $135.05 \pm 93.96$ & $129.16 \pm 92.39$ & 0.7203 \\
$\begin{array}{l}\text { Volume of } \\
\text { distribution }(\mathrm{L} / \mathrm{kg})\end{array}$ & $1 \mathrm{I} .12 \pm 7.48$ & $13.06 \pm 13.25$ & 0.7182 \\
$\begin{array}{l}\text { Aspartate } \\
\text { aminotransferase (U/L) }\end{array}$ & $17 \pm 9$ & $18 \pm 7$ & 0.0718 \\
$\begin{array}{l}\text { Alanine } \\
\text { aminotransferase (U/L) } \\
\gamma \text {-Glutamyltransferase }(\mathrm{U} / \mathrm{L})\end{array}$ & $27.81 \pm 16.79$ & $28 \pm 24$ & 0.3447 \\
$\begin{array}{l}\text { Bilirubin (mg/dL) } \\
0.50 \pm 0.24\end{array}$ & $0.51 \pm 0.23$ & 0.6327 \\
\hline
\end{tabular}


concentrations, especially in patients with CYP2C19 gene mutations. ${ }^{19,20}$ In the Greek population, CYP2C19*2 allele show an allelic frequency of $13.07 \%$ whereas none of 283 subjects studied was found to possess the CYP2C19*3 allele. ${ }^{15}$ Caucasian subjects with $* 1 / * 1$ and $* 1 / * 17$ genotype need stronger acid-suppression therapy compared to CYP2C19*2/*2, especially during the first days of treatment or with on-demand therapy. ${ }^{21}$

Omeprazole is known to have the most pharmacokinetic interactions with TAC, compared to other PPIs. However, Pascual et al estimated the potential interaction between omeprazole and TAC in renal transplant recipients and concluded to absence of important drug interaction between omeprazole and TAC in the general transplant population. ${ }^{10}$ Although other PPIs have fewer documented drug interactions than omeprazole, recently Takahashi et al showed important interactions between lansoprazole and TAC. ${ }^{22}$

In our study, no statistically significant difference was found in the pharmacokinetic parameters of TAC with coadministration of omeprazole. Additionaly, we report no statistically significant difference in hepatic function. Hosohata et al reported that intestinal and graft liver CYP2C19 plays a relatively greater role in the metabolism of omeprazole than it does for lansoprazole, so that the effects of CYP3A5 on the metabolism of TAC might be masked by the interaction with omeprazole associated with the CYP2C19 genotype. ${ }^{23}$ Studies in healthy volunteers suggest that a decrease of dose/ weight normalized trough levels of TAC may be explained by an increase of intestinal CYP3A4 activity. ${ }^{12}$

This was the first attempt to study TAC kinetics in Greek renal transplant patients. CYP3A5*3 is a common polymorphism among Greeks. Detection of CYP2C19 polymorphisms was not performed as a previous study showed that they are rare in Greeks and we assumed that our patients were not CYP2C19 polymorphic. ${ }^{15}$ The absence of CYP3A5 expression was used to reveal the CYP3A4mediated drug interaction between TAC and omeprazole. Although patient's epigenetic characteristics (including age, dietary, and other habits) are known to affect TAC kinetics, these parameters were not studied here because of the small number of patients.

Since genetic information is not usually clinically available for each patient, careful monitoring of TAC trough levels is, still, needed to optimize the dosage regimen in patients receiving TAC. Our results let us propose that there is no need for more frequent therapeutic drug monitoring of TAC when coadministrated with omeprazole in CYP3A5 nonexpressors. However, due to restricted number of patients, prospective studies with greater number of patients and longer observation time are deemed necessary to further evaluate the clinical impact of interaction, if it exists, between TAC and omeprazole.

\section{Acknowledgments}

The authors would like to thank the personnel of the Department of Internal Medicine-Nephrology, University Hospital of Patras, Rion for their support.

\section{Disclosure}

No conflicts of interest were declared in relation to this paper.

\section{References}

1. Ishizaki T, Horai Y. Review article: cytochrome P450 and the metabolism of proton pump inhibitors - emphasis on rabeprazole. Aliment Pharmacol Ther. 1999;13:27-36.

2. Renberg L, Simonsson R, Hoffmann KJ. Identification of two main urinary metabolites of [14C]omeprazole in humans. Drug Metab Dispos. 1989;17:69-76.

3. Andersson T, Miners JO, Veronese ME, et al. Identification of human liver cytochrome P450 isoforms mediating omeprazole metabolism. Br J Clin Pharmacol. 1993;36:521-530.

4. Mourad M, Wallemacq P, De Meyer M, et al. Biotransformation enzymes and drug transporters pharmacogenetics in relation to immunosuppressive drugs: impact on pharmacokinetics and clinical outcome. Transplantation. 2008;85:S19-S24.

5. Tsuchiya N, Satoh S, Tada H, et al. Influence of CYP3A5 and MDR1 (ABCB1) polymorphisms on the pharmacokinetics of tacrolimus in renal transplant recipients. Transplantation. 2004;78:1182-1187.

6. Hu YF, He J, Chen GL, et al. CYP3A5*3 and CYP3A4*18 single nucleotide polymorphisms in a Chinese population. Clin Chim Acta. 2005;353:187-192.

7. Christians U, Schmidt G, Bader A, et al. Identification of drugs inhibiting the in vitro metabolism of tacrolimus by human liver microsomes. Br J Clin Pharmacol. 1996;41:187-190.

8. Matsuda H, Iwasaki K, Shiraga T, Tozuka Z, Hata T, Guengerich FP. Interactions of FK506 (tacrolimus) with clinically important drugs. Res Commun Mol Pathol Pharmacol. 1996;91:57-64.

9. Rost KL, Roots I. Nonlinear kinetics after high-dose omeprazole caused by saturation of genetically variable CYP2C19. Hepatology. 1996;23:1491-1497.

10. Pascual J, Marcén R, Orea OE, et al. Interaction between omeprazole and tacrolimus in renal allograft recipients: a clinical-analytical study. Transplant Proc. 2005;37:3752-3753.

11. Takahashi K, Yano I, Fukuhara Y, et al. Distinct effects of omeprazole and rabeprazole on the tacrolimus blood concentration in a kidney transplant recipient. Drug Metab Pharmacokinet. 2007;22:441-444.

12. Lemahieu WP, Maes BD, Verbeke K, Vanrenterghem Y. Impact of gastric acid suppressants on cytochrome P450 3A4 and P-glycoprotein: consequences for FK506 assimilation. Kidney Int. 2005;67:1152-1160.

13. van Schaik RH, van der Heiden IP, van den Anker JN, Lindemans J. CYP3A5 variant allele frequencies in Dutch Caucasians. Clin Chem. 2002;48:1668-1671.

14. Evans WE, McLeod HL. Pharmacogenomics-drug disposition, drug targets, and side effects. N Engl J Med. 2003;348:538-549.

15. Arvanitidis K, Ragia G, Iordanidou M, et al. Genetic polymorphisms of drug-metabolizing enzymes CYP2D6, CYP2C9, CYP2C19 and CYP3A5 in the Greek population. Fundam Clin Pharmacol. 2007;21:419-426. 
16. Moreau C, Debray D, Loriot MA, Taburet AM, Furlan V. Interaction between tacrolimus and omeprazole in a pediatric liver transplant recipient. Transplantation. 2006;81:487-488. Erratum in: Transplantation. 2006;82:1382.

17. Takahashi K, Motohashi H, Yonezawa A, et al. Lansoprazole-tacrolimus interaction in Japanese transplant recipient with CYP2C19 polymorphism. Ann Pharmacother. 2004;8:791-794. Epub 2004 Mar 9.

18. Itagaki F, Homma M, Yuzawa K, Fukao K, Kohda Y. Drug interaction of tacrolimus and proton pump inhibitors in renal transplant recipients with CYP2C19 gene mutation. Transplant Proc. 2002;34:2777-2778.

19. Furuta T, Ohashi K, Kosuge K, et al. CYP2C19 genotype status and effect of omeprazole on intragastric $\mathrm{pH}$ in humans. Clin Pharmacol Ther. 1999;65:552-561.

20. De Morais SM, Wilkinson GR, Blaisdell J, Meyer UA, Nakamura K, Goldstein JA. Identification of a new genetic defect responsible for the polymorphism of (S)-mephenytoin metabolism in Japanese. Mol Pharmacol. 1994;46:594-598.
21. Hunfeld NG, Mathot RA, Touw DJ, et al. Effect of CYP 2 C $19 * 2$ and * 17 mutations on pharmacodynamics and kinetics of proton pump inhibitors in Caucasians. Br J Clin Pharmacol. 2008;65:752-760. Epub 2008 Jan 30 .

22. van Gelder T. Drug interactions with tacrolimus. Drug Saf. 2002;25: $707-712$.

23. Hosohata K, Masuda S, Katsura T, et al. Impact of intestinal CYP2C19 genotypes on the interaction between tacrolimus and omeprazole, but not lansoprazole, in adult living-donor liver transplant patients. Drug Metab Dispos. 2009;37:821-826. Epub 2009 Jan 12.

\section{Publish your work in this journal}

Therapeutics and Clinical Risk Management is an international, peerreviewed journal of clinical therapeutics and risk management, focusing on concise rapid reporting of clinical studies in all therapeutic areas, outcomes, safety, and programs for the effective, safe, and sustained use of medicines. This journal is indexed on PubMed Central, CAS,

\section{Dovepress}

EMBase, Scopus and the Elsevier Bibliographic databases. The manuscript management system is completely online and includes a very quick and fair peer-review system, which is all easy to use. Visit http://www.dovepress.com/testimonials.php to read real quotes from published authors.

Submit your manuscript here: http://www.dovepress.com/therapeutics-and-clinical-risk-management-journal 